\title{
A proteção jurídica de artesanias certificadas com registro de Indicação Geográfica e o caso da certificação do artesanato do capim dourado das comunidades tradicionais do Jalapão (TO)
}

\author{
Alex Pizzio \\ Universidade Federal do Tocantins - Palmas - Tocantins - Brasil \\ ORCID: 0000-0001-7181-6355 \\ Aline Marinho Bailão Iglesias \\ Tribunal de Justiça do Estado do Tocantins - Palmas - Tocantins - Brasil \\ ORCID: 0000-0001-9371-187x
}

\section{Resumo}

O advento da globalização econômica ampliou o campo de possibilidades de ações com vistas ao desenvolvimento regional. Nesse sentido, muitas regiões têm apostado na implantação do registro de Indicação Geográfica como instrumento capaz de aumentar o dinamismo econômico, contribuindo para o desenvolvimento em termos econômico e social. O objetivo do artigo é avaliar se o registro de Indicação Geográfica de produtos do artesanato é uma ferramenta eficaz na proteção desses produtos e no desenvolvimento sociocomunitário. Na primeira parte do artigo, fazemos uma breve revisão acerca das normas e mecanismos de proteção relacionados à Propriedade Industrial. Na segunda parte, realizamos uma análise a partir de um caso concreto: as artesanias certificadas de capim dourado produzidas pelas comunidades tradicionais do Jalapão, no Tocantins. Os resultados do estudo assinalam que mesmo um instrumento de valoração e proteção de produtos e serviços difundido em escala global, como a IG, oferece uma proteção apenas parcial às artesanias de capim dourado, uma vez que não conseguem coibir infrações como a utilização de recursos naturais protegidos sem a devida autorização, a apropriação de saberes tradicionais e de recursos simbólicos por parte de terceiros e a comercialização de produtos pirateados em mercados internacionais.

Palavras-chave: Proteção jurídica. Indicação Geográfica. Comunidades tradicionais. Capim dourado. Jalapão. 
The legal protection of certified artisans with registration of Geographical Indication and the case of the certification of the handicraft of golden grass in the traditional communities of Jalapão (TO)

\section{Abstract}

The advent of economic globalization has broadened the field of possibilities for actions aimed at regional development. In this sense, many regions have bet on the implementation of the Geographical Indication as an instrument capable of increasing economic dynamism, contributing to development in economic and social terms. The aim of this article is to evaluate whether the registration of Geographical Indication of handicraft products is an effective tool in the protection of these products and in the socio-community development. In the first part of the article, we make a brief review about the agency laws and protection mechanisms related to Industrial Property. In the second part, we carried out an analysis based on a concrete case: the certified golden grass handicrafts produced by the traditional communities of Jalapão, in Tocantins. The results of the study indicate that, even an instrument of valuation and protection of products and services disseminated on a global scale, such as SIG, offers only partial protection to golden grass crafts, since they cannot curb crimes such as the use of protected natural resources without proper authorization, appropriation of traditional knowledge and symbolic resources by third parties and the commercialization of pirated products in international markets.

Keywords: Legal guardianship. Geographical Indication. Traditional communities. Golden grass. Jalapão.

\section{La protección jurídica de los artesanos certificados con el registro de la Indicación Geográfica y el caso de la certificación de la artesanía del oro vegetal en las comunidades tradicionales de Jalapão (TO)}

\section{Resumen}

La globalización económica ha ampliado el campo de posibilidades de acciones encaminadas al desarrollo regional. En este sentido, muchas regiones han apostado por la aplicación de la Indicación Geográfica como un instrumento capaz de aumentar el dinamismo económico, contribuyendo al desarrollo en términos económicos y sociales. El objetivo de este artículo es evaluar si el registro de la Indicación Geográfica de productos artesanales es una herramienta eficaz en la protección de estos productos y en el desarrollo sociocomunitario. En la primera parte del artículo, hacemos una breve revisión sobre las leyes y los mecanismos de protección relacionados con la Propiedad Industrial. En la segunda parte, realizamos un análisis basado en un caso concreto: las artesanas de oro vegetal certificadas, producidas por las comunidades tradicionales de Jalapão, en Tocantins. Los resultados del estudio indican que incluso, un instrumento de valoración y protección de productos y servicios difundidos a escala mundial como la indicación geográfica, sólo ofrece protección parcial a las artesanías de oro vegetal, ya que, no pueden frenar delitos como el uso de recursos naturales protegidos sin la debida autorización, la apropiación de los conocimientos tradicionales y los recursos simbólicos por terceros y la comercialización de productos pirateados en los mercados internacionales.

Palabras clave: Protección legal. Indicación Geográfica. Comunidades tradicionales. Oro vegetal. Jalapão. 


\section{Introdução}

A globalização econômica e a consequente integração dos mercados ampliaram o campo de possibilidades de ações com vistas ao desenvolvimento regional. Nesse sentido, muitas regiões têm apostado na implantação do registro de Indicação Geográfica (IG) como instrumento capaz de incrementar seu dinamismo econômico, contribuindo para o desenvolvimento em termos econômico e social. As Indicações Geográficas são sinais distintivos que protegem a exclusividade de certos produtos cujas qualidades sofrem influência das características locais, sejam fatores naturais ou humanos. Podem ser compreendidas como um instrumento de organização de regiões produtoras, associando os produtos a suas origens como sinônimo de qualidade e diferenciação, uma vez que tendem a "valorizar a diversidade e a singularidade de produtos enraizados em territórios específicos, ressaltando os bens imateriais a eles associados (saber-fazer, tradição, costumes, práticas de produção)" (NIEDERLE, 2014, p. 22). Desse modo, por um lado as IGs agregam valor comercial ao destacar a singularidade do produto e, por outro, oferecem uma proteção especial aos bens produzidos e às regiões produtoras, evitando que produtos similares possam se beneficiar direta ou indiretamente de características e aspectos simbólicos que são próprios de uma determinada região ou comunidade.

Segundo o Instituto Nacional da Propriedade Industrial (Inpi), o registro e a proteção da Indicação Geográfica

\footnotetext{
possibilita agregar valor a ativos intangíveis de uma determinada região, garantindo a produtos e serviços uma identidade que os diferencia, no mercado consumidor, em função de características geográficas, históricas e socioculturais, projetando-as para além de sua área geográfica (SEBRAE; INPI, 2014, p. 9).
}

Trata-se de um instrumento cuja titularidade é coletiva, ou seja, pertence a todos os produtores de uma determinada região. Assim sendo, nenhum produtor poderá dispor ou alienar esse direito de forma privada. Qualquer pessoa que produza ou fabrique um produto protegido pela IG adquire o respectivo direito sobre ela, desde que satisfaça os requisitos impostos pelo seu regulamento de uso. Assim, o direito pertence à pluralidade de produtores de determinada região (STRASBURG JÚNIOR, 2013). Entretanto, apesar da coletividade, trata-se de um interesse privado (não público), cabendo aos integrantes do grupo promover a defesa contra a usurpação de seus direitos exclusivos, de forma que o Estado tem papel secundário na proteção das IGs.

Por atingir, em regra, comunidades de produtores rurais e não raro comunidades tradicionais distantes dos grandes centros, é possível compreender a deficiência na efetivação dos sistemas de proteção desse importante instituto.

\section{0 sistema normativo de proteção das Indicações Geográficas}

As Indicações Geográficas encontram-se resguardadas pelo Direito de Propriedade Intelectual e protegem uma gama variada de produtos corpóreos e incorpóreos contra práticas comerciais ilegais, como a pirataria, por exemplo. A 
Propriedade Intelectual é um dos ramos do Direito voltada a garantir a inventores ou responsáveis por produções do intelecto o direito de obterem as recompensas advindas de sua "criação". Dessa maneira, as IGs encontram-se implicadas diretamente com aspectos de proteção, controle jurídico e fiscalização.

O Direito de Propriedade Intelectual, por sua vez, vincula-se ao Direito Internacional, com o objetivo de ampliar a proteção dos produtos e das criações para além das fronteiras nacionais. Assim, em 1883 foi assinado o primeiro tratado internacional referente à matéria, no evento que ficou conhecido como Convenção de Paris. "Este tratado deu origem ao conhecido Sistema Internacional da Propriedade Intelectual, e foi precursor na tentativa de harmonizar internacionalmente os sistemas jurídicos relativos à Propriedade Industrial" (LIMA; GUIMARÃES; DANTAS, 2015, p. 440).

Segundo Boff et al. (2017), após a II Guerra Mundial, com o avanço da ciência, do comércio e da indústria próprios desse tempo, foram reestruturados os tratados sobre a matéria, tendo como marcos determinantes o Acordo de Lisboa (1958); a criação da Organização Mundial da Propriedade Intelectual em 1967 (OMPI), que em 1974 passou a integrar a ONU com status de Organismo Especializado com a competência para administrar os tratados e convenções sobre a matéria; e o Acordo sobre Aspectos dos Direitos de Propriedade Intelectual Relacionados com 0 Comércio (TRIPS), de 1994.

O último tratado tem grande relevância internacional até os dias atuais. Em sua gênese, o TRIPS buscou garantir proteção aos direitos de propriedade intelectual dentro das relações comerciais. O acordo abordou as seguintes temáticas: Direito do Autor e Direitos Conexos, Marcas, Indicações Geográficas, Desenhos Industriais, Patentes; Topografias de Circuitos Integrados; Proteção de Informação Confidencial; e Controle de Práticas de Concorrência Desleal em Contratos de Licenças. $\mathrm{O}$ acordo vinculou os interesses de proteção da propriedade intelectual ao Acordo Geral sobre Tarifas Alfandegárias e Comércio (GATT) ${ }^{1}$, mais tarde substituído pela Organização Mundial do Comércio (OMC). Nesse sentido, estabelece:

Art. 22

Proteção das Indicações Geográficas

1. Indicações geográficas são, para os efeitos deste Acordo, indicações que identifiquem um produto como originário do território de um Membro, ou região ou localidade deste território, quando determinada qualidade, reputação ou outra característica do produto seja essencialmente atribuída à sua origem geográfica.

2. Com relação às indicações geográficas, os Membros estabelecerão os meios legais para que as partes interessadas possam impedir:

(a) a utilização de qualquer meio que, na designação ou apresentação do produto, indique ou sugira que o produto em questão provém de uma área geográfica distinta do verdadeiro lugar de origem, de uma maneira que conduza o público a erro quanto à origem geográfica do produto;

(b) qualquer uso que constitua um ato de concorrência desleal, no sentido do disposto no Artigo 10bis da Convenção de Paris (1967).

\footnotetext{
${ }^{1}$ Tradução livre da sigla em inglês para General Agreement on Tariffs and Trade.
} 
3. Um Membro recusará ou invalidará, ex officio, se sua legislação assim o permitir, ou a pedido de uma parte interessada, o registro de uma marca que contenha ou consista em indicação geográfica relativa a bens não originários do território indicado, se o uso da indicação na marca para esses bens for de natureza a induzir o público a erro quanto ao verdadeiro lugar de origem.

4. As disposições dos parágrafos 1, 2 e 3 serão aplicadas a uma indicação geográfica que, embora literalmente verdadeira no que se refere ao território, região ou localidade da qual o produto se origina, dê ao público a falsa ideia de que esses bens se originam em outro território (BRASIL, 1994).

Atualmente, cerca de 150 países estão subordinados aos dispositivos do TRIPS, o que representa cerca de $95 \%$ do comércio internacional. Esse acordo é parte integrante do Acordo Constitutivo da Organização Mundial do Comércio (OMC), do qual o Brasil é signatário. Os tratados internacionais estabelecem formas mínimas de proteção e sua aplicabilidade ainda é recente, de forma que, mesmo com a amplitude internacional alcançada pelo TRIPs, a proteção efetiva ainda se mostra incipiente. Não existe um registro internacional único ou selo único para produtos registrados. De acordo com Belas (2012), a ausência do registro internacional contribui para uma heterogeneidade de procedimentos e regras para concessão de IGs entre os países. Tal fato gera dificuldades em se garantir equilíbrio e proteção aos produtos, uma vez que cada país desenha internamente a proteção de suas IGs, conforme os interesses locais.

No Brasil, as primeiras menções à proteção de nomes geográficos apareceram no Código de Propriedade Industrial de 1967 e em seguida instituiu-se o Código de 1971 (Lei $n^{\circ}$ 5.772/71), que seguiu os mesmos princípios anteriores. Em 14 de maio de 1996, derivada das orientações advindas do Acordo Internacional da TRIPS/ADIPC (1994), é publicada a Lei da Propriedade Industrial (LPI n. 9.279/1996). A normativa foi inovadora quanto à proteção de IGs porque não restringiu a repressão às falsas indicações, mas também se preocupou em constituir um sistema controlado para o registro.

A LPI conferiu ao Instituto Nacional da Propriedade Industrial (Inpi), autarquia federal vinculada ao Ministério da Economia, a atribuição de estabelecer as condições para os registros de Indicações Geográficas, bem como efetivar o registro (BRASIL, 1996). Dois anos depois, surge a primeira regulamentação para o registro das IGs, o Ato Normativo $n^{\circ} 143 / 98$. O Regulamento de Registro tem sofrido constantes modificações, estando atualmente em vigência a Instrução Normativa INPI/PR n. 95/2018, de 28 de dezembro de 2018, e a Resolução INPI/PR n 233/2019, de 18 de janeiro de 2019 (esta última tratando sobre o peticionamento eletrônico).

Nesse sentido, por ser relevante para o desenvolvimento econômico,

este Instituto se faz importante não só para as grandes empresas, mas também para as micro e pequenas empresas, além de empreendedores individuais, que por meio do auxílio do INPI podem formar parcerias e crescer frente ao mercado competitivo, no qual é praticamente impossível competir apenas pelo preço. No mais, o foco do Instituto é atrair pesquisadores e empreendedores que possam se beneficiar com o conhecimento e o uso da propriedade intelectual (LIMA; GUIMARÃES; DANTAS, 2015, p. 446). 
Seguindo na mesma linha de argumentação, observa-se no processo de evolução do regramento nacional de proteção intelectual que a LPI deixou de conceituar o Gênero Indicações Geográficas e passou a conceituar as IGs em duas espécies subdivididas: Indicação de Procedência (IP) e Denominação de Origem (DO).

\begin{abstract}
Art. 177. Considera-se indicação de procedência o nome geográfico de país, cidade, região ou localidade de seu território, que se tenha tornado conhecido como centro de extração, produção ou fabricação de determinado produto ou de prestação de determinado serviço.

Art. 178. Considera-se denominação de origem o nome geográfico de país, cidade, região ou localidade de seu território, que designe produto ou serviço cujas qualidades ou características se devam exclusiva ou essencialmente ao meio geográfico, incluídos fatores naturais e humanos (BRASIL, 1996).
\end{abstract}

Assim, a Denominação de Origem (DO) é atribuída “ao produto cuja produção, transformação e elaboração ocorrem numa área geográfica delimitada, com um 'saber fazer' reconhecido e verificado" (FABRIS, MACHADO, GOMES, 2012, p. 389). Esse registro possui requisitos rígidos de verificação dos fatores geográficos e humanos referentes à procedência, especialmente questões ligadas à qualidade do produto ou serviço. A Indicação de Procedência (IP) relaciona o produto ao meio geográfico em uma de suas fases de produção, transformação ou elaboração. Valoriza a tradição produtiva da região em que está inserida, dando menos importância ao aspecto da qualidade para validação do registro.

Do ponto de vista de políticas públicas de proteção e controle do patrimônio cultural brasileiro, a Secretaria Especial da Cultura atua por meio do Instituto do Patrimônio Histórico e Artístico Nacional (IPHAN). Nesse contexto, os produtos artesanais foram beneficiados com a instituição do Registro de Bens Culturais de Natureza Imaterial, através do Decreto n. 3.551/2000, que se materializou nos Livros de Registros do Patrimônio Imaterial: Livro de Registro dos Saberes, Livro de Registro das Celebrações, Livro de Registro de Formas de Expressão e Livro de Registro dos Lugares (BRASIL, 2000). O registro nos livros confere ao patrimônio imaterial - no caso do artesanato, "o modo de fazer" - o status oficial de patrimônio cultural brasileiro, o que garante a sua preservação e memória de sua origem para as futuras gerações.

\title{
2.1 Responsabilidade civil, penal e administrativa
}

Além do fomento e valorização dos produtos, a proteção normativa visa também o estabelecimento de um sistema de repressão, a fim de coibir falsificações, fraudes e a concorrência desleal. Dessa maneira, a violação às normas de proteção deve gerar a responsabilização do infrator nas esferas civil, administrativa e criminal. A responsabilidade jurídica refere-se à situação do agente que, violando uma obrigação ou uma norma, tende a sofrer consequências desagradáveis decorrentes dessa violação, opostas pela autoridade encarregada na fiscalização de determinada atividade. "Responsabilidade então exprime a ideia de restauração de equilíbrio, de contraprestação, e de reparação de dano. Sendo 
múltiplas as atividades humanas, inúmeras serão também as espécies de responsabilidade" (GOMES, 2020, p. 76).

Apesar da variedade de normas e tratados que se referem às Indicações Geográficas, é possível delimitar a tutela jurídica do instituto nos âmbitos administrativo, penal e civil. As três esferas são independentes, de forma que o violador poderá responder de forma isolada ou simultaneamente. Assim, após a violação à norma e a prática de atividade ilícita ou abusiva, torna-se necessária a atuação de autoridades competentes para a aplicação de medidas punitivas capazes de trazer de volta o equilíbrio rompido com a violação de direitos. A responsabilidade administrativa resulta da infração de normas administrativas, sujeitando o violador a uma sanção também de natureza administrativa cujos exemplos mais comuns são a advertência, multa, interdição de atividades e suspensão de benefícios. Todos os entes estatais possuem Poder de Polícia que se refere à matéria que lhes cabe regular. Nesse sentido, o Poder de Polícia "deve ser entendido como a atividade da Administração Pública que, por meio de atos, impõe limites ao exercício de direitos e liberdades do particular. Tal atividade pode, ainda, ser entendida como uma faculdade de que dispõe a administração" (GOMES; DUTRA, 2017, p. 91).

Na perspectiva acima, a responsabilização civil e penal depende da atuação ostensiva do Poder Judiciário através das ações judiciais correspondentes. A responsabilidade civil diz respeito ao ato de infringir uma obrigação contratual ou legal, gerando dano ou risco de ordem material, moral ou estética a um indivíduo ou conjunto de indivíduos. Tal infração gera ao infrator a necessidade de reparação civil. Segundo o Código Civil brasileiro:

\footnotetext{
Art. 927. Aquele que, por ato ilícito (arts. 186 e 187), causar dano a outrem, fica obrigado a repará-lo.

Parágrafo único. Haverá obrigação de reparar o dano, independentemente de culpa, nos casos especificados em lei, ou quando a atividade normalmente desenvolvida pelo autor do dano implicar, por sua natureza, risco para os direitos de outrem (BRASIL, 2002).
}

A LPI ainda dispõe sobre o direito ao ressarcimento dos prejuízos causados exclusivamente pela violação de direitos de propriedade industrial e concorrência desleal:

\begin{abstract}
Art. 209. Fica ressalvado ao prejudicado o direito de haver perdas e danos em ressarcimento de prejuízos causados por atos de violação de direitos de propriedade industrial e atos de concorrência desleal não previstos nesta Lei, tendentes a prejudicar a reputação ou os negócios alheios, a criar confusão entre estabelecimentos comerciais, industriais ou prestadores de serviço, ou entre os produtos e serviços postos no comércio (BRASIL, 1996).
\end{abstract}

As associações gestoras das IGs e o Ministério Público têm papel fundamental para garantir a responsabilização dos agentes que causem dano à cadeia produtiva regulada pela IG, bem como para promover o ressarcimento e cessação da atividade ilícita. Além das ações ordinárias de ressarcimento fundamentadas no Código Civil e na LPI, têm como instrumento eficaz na proteção 
do meio ambiente e dos direitos de valor histórico e artístico a Ação Civil Pública disciplinada pela Lei n. 7.347/1985:

Art. $1^{\circ}$ Regem-se pelas disposições desta Lei, sem prejuízo da ação popular, as ações de responsabilidade por danos morais e patrimoniais causados:

$[\ldots]$

IV - a qualquer outro interesse difuso ou coletivo.

$\checkmark$ - por infração da ordem econômica.

[...]

Art. $5^{\circ}$ Têm legitimidade para propor a ação principal e a ação cautelar: I - o Ministério Público;

$[\ldots]$

$V$ - a associação que, concomitantemente:

a) esteja constituída há pelo menos 1 (um) ano nos termos da lei civil;

b) inclua, entre suas finalidades institucionais, a proteção ao patrimônio público e social, ao meio ambiente, ao consumidor, à ordem econômica, à livre concorrência, aos direitos de grupos raciais, étnicos ou religiosos ou ao patrimônio artístico, estético, histórico, turístico e paisagístico (BRASIL, 1985).

Esses instrumentos legais são capazes de garantir a preservação do direito de exclusividade pretendido com o registro da Indicação Geográfica e estão dispostos tanto na LPI como nas normativas estaduais de proteção e nos próprios regulamentos de uso de cada IG. Pode-se dizer que o Brasil

conta com uma lei atualizada para a defesa dos direitos da propriedade industrial e, em especial, das indicações geográficas, sendo necessário, todavia, que o instituto seja conhecido e corretamente empregado, com o seu uso incentivado pelo Poder Público e por entidades representantes dos setores interessados como vem ocorrendo, há décadas, nos países com maior tradição agrícola da Europa (STRASBURG JÚNIOR, 2013, p. 43).

Quanto à responsabilização penal, envolve o dever jurídico de responder e ser punido em razão da prática de ato definido como crime pela lei. Além dos crimes ambientais que, eventualmente, possam ocorrer dentro da cadeia produtiva da Indicação Geográfica, a LPI define crimes específicos para a proteção de IGs:

Art. 192. Fabricar, importar, exportar, vender, expor ou oferecer à venda ou ter em estoque produto que apresente falsa indicação geográfica.

Pena - detenção, de 1 (um) a 3 (três) meses, ou multa.

Art. 193. Usar, em produto, recipiente, invólucro, cinta, rótulo, fatura, circular, cartaz ou em outro meio de divulgação ou propaganda, termos retificativos, tais como "tipo", "espécie", "gênero", "sistema", "semelhante", "sucedâneo", "idêntico", ou equivalente, não ressalvando a verdadeira procedência do produto.

Pena - detenção, de 1 (um) a 3 (três) meses, ou multa.

Art. 194. Usar marca, nome comercial, título de estabelecimento, insígnia, expressão ou sinal de propaganda ou qualquer outra forma que indique procedência que não a verdadeira, ou vender ou expor à venda produto com esses sinais.

Pena - detenção, de 1 (um) a 3 (três) meses, ou multa (BRASIL, 1996). 
Ademais, aquele que viola as normas penais de proteção das IGs poderá ainda responder por concorrência desleal, cujo crime se encontra previsto no art. 195 da LPI. O Estado estimula a concorrência como forma de fomentar e estimular o aprimoramento das atividades comerciais, industriais e tecnológicas, entretanto deve reprimir a concorrência feita de forma ilícita, contrária às práticas honestas, tendo como fundamento o art. $173, \S 4^{\circ}$ da Constituição Federal: "a lei reprimirá o abuso do poder econômico que vise à dominação de mercados, à eliminação da concorrência e ao aumento arbitrário de lucros".

Ao Poder Judiciário cabe a análise de ações civis e criminais de responsabilização. Algumas questões têm prejudicado a tutela jurisdicional desses direitos. Controvérsias sobre a competência estadual ou federal para dirimir os conflitos atrasam o andamento dessas ações. Também se observa que a maioria dos crimes previstos é de ação penal privada, dependendo do interesse da vítima para a sua deflagração, o que, aliado às baixas penas, serve de desestímulo para a procura da responsabilização no campo penal.

Cardoso (2008, p. 56) assinala como prejudicial a quantidade de atos normativos e instituições existentes. "Tais distinções criam empecilhos à proteção e à atuação uniforme quanto aos direitos da propriedade intelectual, causando insegurança jurídica e não conferindo a necessária tutela", de forma que as ações para proteção de Indicações Geográficas são bastante incomuns no Poder Judiciário, apesar da ostensiva legislação existente.

\section{Controle e proteção jurídica das IGs de produtos não alimentares}

No âmbito da União Europeia são mantidos atualmente quatro sistemas de proteção de Indicações Geográficas, mas todos eles se ligam ao setor de alimentos e bebidas, não havendo até o momento proteção para produtos não alimentícios, como é o caso do artesanato ${ }^{2}$. De acordo com Carls (2016), o Sistema Comunitário de Proteção compreende: as normativas referentes a Vinhos - Regulamento (UE) n. 1.308/2013; Destilados - Regulamento (CE) n. 110/2008; Produtos vitivinícolas aromatizados - Regulamento (UE) n. 251/2014; e Produtos agrícolas e gêneros alimentícios - Regulamento (UE) n. 1.151/2012. Sem a devida proteção, os produtos não alimentícios se socorrem do "(i) regime comunitário de marcas, que confere proteção a nomes geográficos sob certas condições; (ii) litígio judicial; ou (iii) procedimento via autoridade administrativa no caso de prática desleal ou engano ao consumidor" (CARLS, 2016, p. 98).

Nessa mesma linha, Belas (2012) afirma que alguns países europeus têm criado estratégias de proteção com sistemas sui generis de reconhecimento de IGs para produtos de artesanatos como rendas, bordados, cerâmica, cristais e outros. Entretanto, não reconhecidos pelo Sistema Comunitário, ficam restritos ao âmbito do país de origem, sendo ineptas em relações internacionais.

Entre os estudos que buscaram estender a proteção aos produtos não alimentícios na Europa, destacam-se o Study on the protection of geographical

\footnotetext{
2 Sobre a utilização de legislação não específica para produtos não alimentares, no plano internacional, ver: Bhat; Singh (2017).
} 
indications for products other than wines, spirits, agricultural products or foodstuffs ${ }^{3}$, publicado em 2009, e o Study on geographical indications protection for nonagricultural products in the internal market, ${ }^{4}$ publicado em 2013. Ambos, encomendados pela Diretoria Geral de Comércio da Comissão Europeia, realizaram análises aprofundadas sobre o tema, com a participação de países europeus e, também, países terceiros, entre eles o Brasil. Na prática, a situação permanece pendente de solução adequada. Mesmo diante de diversas manifestações favoráveis, bem como da necessidade de atender ao TRIPS, nada foi feito até o momento no sentido de estender formalmente a proteção das Indicações Geográficas aos produtos não agroalimentares no cenário comunitário (CARLS, 2016).

No Brasil, a Lei de Propriedade Industrial não distinguiu a proteção entre produtos alimentícios ou artesanias, incluindo também a possibilidade de certificação de serviços. De acordo com o Catálogo de Indicações Geográficas Brasileiras, tem-se até dezembro de 2019 o total de 55 Indicações de Procedência reconhecidas, sendo todas nacionais; e 21 Denominações de Origem, com 12 nacionais e 9 estrangeiras. Entre estas, a grande maioria trata de produtos alimentícios como café, queijos, carne, cachaça, vinhos e doces. Existem ainda IGs que se referem à extração de minérios e fabricação de produtos comerciáveis, como calçados. Mas não há nenhuma DO que se refira a artesanatos e, entre as IPs, apenas 8 se referem a artesanatos: a renda renascença do Cariri, na Paraíba; as panelas de barro de Goiabeiras, no Espírito Santo; as peças artesanais de estanho de São João del-Rei, em Minas Gerais; as joias de opala de Pedro II, no Piauí; a renda de agulha em lacê de Divina Pastora, em Sergipe; o bordado filé das lagoas MundaúManguaba, em Alagoas; as joias artesanais de prata de Pirenópolis, em Goiás; e o artesanato de capim dourado do Jalapão, no Tocantins. Nesses locais, a produção se revela parte da cultura das comunidades, o que demonstra a sua valorização tanto econômica como identitária. Segundo Belas (2012, p. 21),

O fato de a IG constituir um dos raros mecanismos do sistema de propriedade intelectual que permitem alguma forma de proteção a produções coletivas, históricas e localizadas, trouxe à tona a perspectiva do uso desse instrumento para a proteção de produtos desenvolvidos por povos e comunidades tradicionais. Tal mecanismo é percebido como uma forma de se evitar apropriações ilícitas e de se garantir uma adequada repartição de benefícios aos detentores de modos de fazer, preservados e transmitidos ao longo de gerações.

No entanto, é importante destacar que a proteção conferida pela Indicação Geográfica se limita ao país de registro, salvo a existência de acordos e tratados internacionais específicos, por isso alguns produtos estrangeiros possuem registro no Brasil. Em relação aos produtos brasileiros, havendo o interesse público em que se tenha o seu registro reconhecido na Europa, se faz necessária a proposição pelas autoridades brasileiras junto à Comissão Europeia, que procede à apreciação e

\footnotetext{
${ }^{3}$ Estudo sobre a proteção das indicações geográficas para além dos vinhos, bebidas destiladas, produtos agrícolas e gêneros alimentícios (tradução livre).

${ }^{4}$ Estudo sobre a proteção de indicações geográficas não agroalimentares no mercado interno (tradução livre).
} 
avaliação dessas IGs na perspectiva do Sistema Comunitário Europeu. Entretanto, esse caminho ainda não pode ser utilizado para IGs de produtos não alimentícios, que ainda não são contemplados pelo Sistema Comunitário de Proteção. Dessa forma, atualmente não é possível o registro de IG de artesanatos de países terceiros para proteção em países europeus, ressalvada a possibilidade de verificação de normativas internas de cada país-membro, o que se traduz numa forma bastante ineficiente.

\section{A indicação de procedência de artesanias: o caso do artesanato do capim dourado no Jalapão (TO)}

$\mathrm{O}$ artesanato de capim dourado no estado do Tocantins teve origem na arte dos índios Xerente, transmitida a moradores da comunidade Mumbuca, na região do Jalapão. Nessa área de remanescentes quilombolas, a artesania vem sendo passada de geração a geração desde meados de 1920. O capim dourado é uma sempre-viva da família das eriocaláceas (Syngonanthus nitens) e o artesanato é produzido pela costura manual das hastes do capim com uma fibra obtida de folhas da palmeira buriti (Mauritia flexuosa) (FIGUEIREDO, 2009, p. 2). São produzidos cestos, potes, fruteiras, mandalas, bolsas, objetos de decoração, enfeites de cabelo e as chamadas biojoias ou ecojoias.

Conforme relatam Pizzio e Lopes (2018), a disseminação do artesanato do capim dourado se liga diretamente às atividades turísticas no Jalapão. Um dos fatos que contribuíram para a sua visibilidade foi uma reportagem do programa televisivo Globo Repórter, em 1990, que mostrou a rica diversidade natural da região, divulgando-a como um atraente destino turístico. A partir de então houve um expressivo aumento na difusão do artesanato, de modo que sua venda passou a ter papel fundamental na economia de vários municípios jalapoeiros (MELLO, 2015). Já nos anos 2000, as peças começaram a ser exibidas de maneira globalizada em vitrines de áreas de grande circulação comercial e shopping centers, além de lojas de aeroportos (PIZZIO; LOPES, 2018).

Silva e Rodrigues (2017) afirmam que o extrativismo do capim dourado ocorreu livremente até final dos anos 1990, quando a produção comercial do artesanato foi estimulada pelas ações do governo do estado do Tocantins e das prefeituras locais. A partir desse momento, foram necessárias ações governamentais no sentido de garantir a sustentabilidade ambiental da região, como a criação da Área de Proteção Ambiental do Jalapão, pela Lei n. 1.172/2000, e do Parque Estadual do Jalapão, consolidado pela Lei 1.203/2001 (TOCANTINS, 2000; 2001).

O Jalapão é uma região caracterizada pela predominância de Cerrado Ralo e Campo Limpo com veredas, pontilhada por oásis e recortada por uma imensa teia de rios, riachos e ribeirões de água límpida e transparente. As áreas de proteção colaboram para a preservação da natureza e garantem a exploração ordenada do capim dourado e das atividades turísticas ligadas à exploração da beleza de suas dunas, cachoeiras e fervedouros.

Em 30 de agosto de 2011, foi concedido o registro da Indicação Geográfica ao artesanato de capim dourado da região do Jalapão, na modalidade de Indicação de Procedência, considerando-se as limitações geográficas e o Regulamento Técnico 
do Controle de Qualidade do Artesanato de Capim Dourado publicado pela Fundação Cultural do Estado do Tocantins, através da Portaria n. 04, de 18 de fevereiro de 2009. O regulamento abarca os municípios tocantinenses de Santa Tereza do Tocantins, Lagoa do Tocantins, Novo Acordo, Mateiros, Ponte Alta do Tocantins, São Félix do Tocantins, Lizarda e Rio Sono (TOCANTINS, 2009). O registro buscou o reconhecimento do artesanato com o fim de garantir exclusividade na comercialização pelos produtores locais, além da qualidade e a fidelização do produto. A limitação da área tem por objetivo garantir proteção ao meio ambiente através da regulamentação do extrativismo do capim dourado, que como bem público de uso coletivo é finito e necessita do uso sustentável. Por outro lado, pretendeu-se resguardar o patrimônio cultural, conferindo identidade ao produto e à arte oriundos das tradições e memórias dessa região.

A Indicação Geográfica para as artesanias do Jalapão, muito além de organizar o comércio, constitui uma política pública que pretende resguardar o patrimônio cultural imaterial que reveste a atividade e que tem por beneficiários não apenas a comunidade local, mas toda a sociedade brasileira. Trata-se claramente de uma política de governo para proteção da tradição e da cultura. Entretanto, no Brasil - em especial no caso do estado do Tocantins -, há poucas políticas voltadas para o conhecimento desse instrumento de diferenciação (PERALTA, 2016). Na falta de estímulos governamentais, os agentes locais se organizam como podem e tentam traçar diretrizes para o uso e reconhecimento dos sinais distintivos, mas a proteção da IG fica comprometida.

\begin{abstract}
Enquanto produção de atores provindos das camadas populares, estes agentes, [...], internalizam as categorias desenvolvidas por intelectuais sem maiores reflexões. [...] Em busca do reconhecimento para a sua produção, tais agentes tomam para si termos como cultura popular e patrimônio imaterial, mesmo sem digeri-los plenamente, na tentativa de reivindicar políticas culturais de fomento baseadas nas categorias dos intelectuais que os estudam (PERALTA, 2016, p. 1.710).
\end{abstract}

A Associação dos Artesãos em Capim Dourado da Região do Jalapão, Estado de Tocantins (Areja) é o organismo institucional responsável pela Indicação de Procedência do Capim Dourado. Ao avaliar aspectos da performance institucional, Silva e Rodrigues (2017) constataram diversas fragilidades em sua governança interna. Foram destacados pelos autores a inexistência de mecanismos para resolução de conflitos entre os produtores ou entre estes e os administradores; ausência de alinhamento das instituições em torno da IG; falta de fiscalização das atividades dos artesãos; ausência de monitoramento e delação de infrações pelos próprios artesãos à Administração; e a falta de sanções graduais e do uso de mediação.

Avaliando os princípios organizacionais e a performance da Areja, verificase que a instituição delineada para gerir a indicação de procedência dos artesanatos em capim dourado da Região do Jalapão abarca poucos princípios básicos. Isso prejudica sobremaneira a governança da indicação geográfica, corroborando para a fragilização da performance institucional (SILVA; RODRIGUES, 2017, p. 16).

Uma tentativa de fazer com que a Areja adquirisse maior dinâmica e impulsionasse a implantação de um Selo de Indicação Geográfica (SIG) foi 
formulada em abril de 2015, quando a Secretaria de Estado da Cultura do Tocantins e a Universidade Federal do Tocantins (UFT) assinaram um termo de cooperação técnica. O Selo de Indicação Geográfica (SIG) seria utilizado pelos artesãos da região, valorizando os produtos lá produzidos, de forma que fossem reconhecidos em mercados nacionais e internacionais (PIZZIO; LOPES, 2018).

A fragilidade do ambiente institucional tem reflexos imediatos na proteção e tutela jurídica da IG. Se não há fiscalização das atividades nem espaço interno para resolução de conflitos, a responsabilização de agentes infratores das normas regulatórias tende a inexistir. Além da ausência de repressão administrativa pelas entidades gestoras, também são mínimas as ações judiciais, denúncias e investigações tendentes à responsabilização civil e penal que chegam ao Poder Judiciário.

Ao consultar o banco de dados do Ministério Público das circunscrições judiciárias que englobam os municípios participantes da Indicação de Procedência dos artesanatos de capim dourado, não encontramos registros de denúncias relativas à transgressão de normas de proteção da IP. Entretanto, constatou-se a ocorrência de casos relacionados a infrações ambientais (extração irregular do capim dourado) nas cidades de Ponte Alta do Tocantins e Mateiros.

Além das normas nacionais e federais de proteção já comentadas, a IP do artesanato de capim dourado conta com normativas próprias estaduais, entre elas a Portaria n. 362, de 25 de maio de 2007, do Instituto Natureza do Tocantins (Naturatins) $)^{5}$, o Regulamento Técnico do Controle de Qualidade - Portaria n. 04/2009 da Fundação Cultural do Tocantins e o Regulamento Geral de Uso da Indicação Geográfica da Areja. Esses atos restringem o acesso à matéria-prima e à forma de manufatura, visando à proteção da exclusividade e da tradição.

O Regulamento Técnico do Controle de Qualidade prevê a técnica de costura exclusivamente manual como padrão de qualidade a ser aferido por representante da Fundação Cultural do Tocantins (TOCANTINS, 2009). O Regulamento Geral de Uso proíbe expressamente o comércio e o transporte do vegetal capim dourado ou o olho do buriti por terceiros que não sejam artesãos devidamente cadastrados no Naturatins, estando vigente desde $1^{\circ}$ de dezembro de 2008 (TOCANTINS, 2008). A Portaria n. 362/2007 do Naturatins também proíbe a comercialização e o transporte do capim dourado in natura por pessoas não cadastradas, bem como especifica o período e a forma de coleta do capim dourado (TOCANTINS, 2007).

Apesar de todas essas normas específicas de proteção estadual, não há divulgação de responsabilização de terceiros infratores. Não obstante, há indícios de atividades ilícitas capazes de gerar graves prejuízos aos artesãos cadastrados. Um exemplo que ilustra bem o problema em tela é o caso da marca italiana Capim d'Oro, dedicada à produção de joias semipreciosas com design italiano e produzidas com capim dourado. Segundo a empresa, a

Capim d'Oro nasceu do encontro de um inconfundível estilo MADE IN ITALY e da particularidade da planta brasileira Capim Dourado. A fibra natural, também conhecida como "ouro vegetal", cresce

\footnotetext{
${ }^{5}$ Autarquia do estado do Tocantins responsável pela execução de políticas públicas voltadas para a preservação e conservação dos recursos naturais.
} 
espontaneamente numa única área do mundo: na região do Jalapão, no estado do Tocantins, no Brasil (CAPIM D'ORO, N. D.).

Com ampla divulgação nas redes sociais, a empresa oferece, em site comercial, uma variedade de produtos tidos como exclusivos: brincos, anéis, pulseiras, colares, malas e acessórios para cabelo, vasos e cestas, trançados de maneira semelhante à do artesanato jalapoeiro e cuja criação é atribuída a designers italianos:

\begin{abstract}
Nossas criações artesanais são a quintessência do artesanato e nascem do estudo cuidadoso do material, da personalização dos detalhes e da seleção meticulosa da fibra vegetal. Toda joia tecida à mão, sem o auxílio de máquinas, requer uma precisão sábia adquirida diretamente no Brasil e aperfeiçoada graças aos estudos em Design Industrial, na faculdade Ludovico Quaroni - La Sapienza, em Roma. Em 2013, iniciou-se o laboratório em Roma, a fim de permitir o conhecimento desse processo muito particular, iniciado pelos índios e que está expandindo cada vez mais seus mercados, inclusive para jovens artesãos. $O$ produto semiacabado que vem diretamente do Brasil é de fato processado em nosso laboratório em Roma por jovens aprendizes, que habilmente tecem a fibra vegetal. Anualmente, vamos duas vezes à região de Jalapão, onde escolhemos pessoalmente as melhores fibras vegetais. $O$ suprimento de matéria-prima é essencial, pois muitas vezes a colheita está arruinada devido às estações ruins e, portanto, é essencial ter o capim dourado disponível para os anos seguintes. [...] O capim dourado está se tornando cada vez mais um protagonista internacional das joias e é combinado com pedras e swarovski, mas queríamos oferecer em nossas coleções artesanais também a criação de objetos domésticos para a vida cotidiana, como foi originalmente feito pelos índios. De fato, em nossas coleções você também pode encontrar vasos e cestas (CAPIM D'ORO, N. D., tradução e grifos nossos).
\end{abstract}

Como se pode observar, o trecho anterior parece indicar usurpação de um direito de propriedade intelectual brasileiro, patrimônio cultural do Jalapão. Em termos legais, há fortes indícios de uma série de violações: o transporte e a comercialização do capim dourado in natura, um recurso natural protegido; a apropriação de saberes tradicionais e recursos simbólicos, uma vez que a técnica do trançado utilizado na fabricação é atribuída à Comunidade Mumbuca. Ainda, entende-se que o direito de imagem $^{6}$ dos comunitários foi infringido e utilizado, sem a devida autorização, para fins de promoção dos produtos da empresa. Em relação a esse último aspecto, esclarecemos que somente em 2017 a comunidade tomou conhecimento da existência da empresa e da produção desses artigos. ${ }^{7}$

\footnotetext{
${ }^{6}$ O direito de imagem, consagrado e protegido pela Constituição de 1988 e pelo Código Civil brasileiro de 2002 como um direito de personalidade autônomo, trata da projeção da personalidade física da pessoa, incluindo os traços fisionômicos, o corpo, atitudes, gestos, sorrisos, indumentárias etc.

${ }^{7}$ Em setembro de 2017, em visita de campo para realização de atividades de pesquisa, foi indagado a uma liderança comunitária sobre uma possível relação da referida empresa com a comunidade. Para surpresa dos pesquisadores, os jalapoeiros não tinham nenhum conhecimento da empresa, tampouco da existência de um vídeo promocional que apresenta imagens obtidas no local (da comunidade e dos processos de fabricação de artesanato). O vídeo pode ser visto no endereço: www.youtube.com/watch?v=6qYfXyinYb8. Acesso em: 29 abr. 2020.
} 
É certo que o artesanato de capim dourado não possui registro de IG na União Europeia e, conforme já demonstrado, não há proteção comunitária ao artesanato. Assim, os tratados internacionais não estariam sendo transgredidos pela empresa citada. Entretanto, várias são as possibilidades de investigação e possível responsabilização diante das normas nacionais e estaduais, em especial a venda do produto in natura para terceiros não artesãos. A ausência de fiscalização e de operacionalização do sistema de responsabilização gera descrédito e insegurança jurídica, prejudicando os objetivos esperados com o registro da Indicação Geográfica.

Recentemente foi publicada a Lei Estadual n. 3.594, de 18 de dezembro de 2019, que dispõe sobre a política de uso sustentável do capim dourado e do buriti, tornando proibida a saída do capim dourado in natura do estado do Tocantins:

\footnotetext{
Art. 17

$\S 1^{\circ}$ Ficam proibidos o transporte e a comercialização das hastes de capim dourado in natura, assim entendidas como aquelas coletadas no Tocantins e, antes da confecção de artesanato, enviadas para fora do Estado do Tocantins (TOCANTINS, 2019).
}

É de se observar que a nova lei evidenciou proibições que já constavam em normas anteriores. Pretende-se com essa normativa ampliar os mecanismos de proteção e a capacidade fiscalizadora dos órgãos de proteção local, em especial do Naturatins. Nesse sentido, entende-se que a atuação de organismos de repressão aumenta a segurança jurídica aos produtores e aos consumidores, pois relaciona-se fortemente ao desenvolvimento da produção e da comercialização.

\section{Considerações finais}

O debate sobre as estratégias de proteção para Indicações Geográficas se encontra ainda em estágio embrionário no Brasil e muitos desafios se apresentam, tanto de natureza mercadológica como de responsabilização daqueles que violam as normas protetivas. Verificou-se a necessidade de se levar aos produtores certificados o conhecimento sobre os mecanismos de proteção disponíveis, quais são os órgãos fiscalizadores aptos a receber denúncias e reclamações, bem como as possibilidades de ações de ressarcimento e punição de violadores dos regulamentos das IGs.

A existência de normas protetivas se torna inócua quando não são capazes de abranger as complexidades relacionadas a casos concretos. O fato de abranger interesses coletivos como o meio ambiente e o uso de recursos naturais aumenta o grau de complexidade. Nessa perspectiva, faz-se necessária a ampliação de estudos que abordem a eficácia e a efetividade dos mecanismos de proteção, bem dos órgãos fiscalizadores das IGs. O caso do artesanato do capim dourado se enquadra nesse contexto. Para comunidades e/ou grupos como a Mumbuca, fica a sensação de que a proteção depende exclusivamente dos órgãos estatais, entretanto, no complexo sistema normativo de proteção das IGs, as ações são em regra de iniciativa privada, sendo necessário que os produtores sejam informados a respeito dos mecanismos de proteção e assumam o protagonismo de atuar na defesa do produto registrado. 
Além do interesse privado, deve-se considerar também o interesse/obrigação estatal em estimular o aprimoramento das atividades comerciais, industriais e tecnológicas através da livre concorrência, sendo seu dever constitucional reprimir a concorrência desleal. Assim, demonstra-se a necessidade do apoio governamental e do Ministério Público no combate às práticas comerciais desonestas e na responsabilização dos infratores.

Enquanto isso não ocorre, atividades ilícitas permanecem sem punição, a despeito da existência de normas de proteção, e em proporções até então desconhecidas - como pode ser observado no comércio de produtos fabricados com o capim dourado do Jalapão e vendidos por empresas estrangeiras, que assim infringem a exclusividade garantida pela Indicação de Procedência e a proibição legal da saída do capim in natura da área protegida. A IP dos artesanatos de capim dourado tem grande importância como alternativa de sustento da população local e promoção turística da região, além de resguardar um patrimônio cultural e intelectual e constituir-se em uma estratégia de desenvolvimento regional, o que não pode ser usurpado pela concorrência ilegal e a falsificação. O enfrentamento desses desafios é possível com a implementação de políticas públicas, principalmente na fase de pós-registro, levando aos produtores as informações necessárias para a preservação constante da IG, além da ideia principal do protagonismo de cada produtor no desenvolvimento e proteção do seu patrimônio intelectual.

\section{REFERÊNCIAS}

BELAS, Carla Arouca. Indicações geográficas e a salvaguarda do patrimônio cultural: artesanato de capim dourado - Jalapão-Brasil. 266 f. Tese (Doutorado em Ciências) - Universidade Federal Rural do Rio de Janeiro, Rio de Janeiro, 2012.

BHAT, Ishfaq Hussain; SINGH, Sapna. A study on branding of handicraft through geographic indication with reference to Kashmir. International Journal of Information, Business and Management, v. 9, n. 4, p. 275-283, nov. 2017

BOFF, Salete Oro; FORTES, Vinícius Borges; MENEGAZZO, André Frandoloso; TOCHETTO, Gabriel Zanatta. Propriedade intelectual: marcos regulatórios. Erechim: Deviant, 2017.

BRASIL. Decreto n. 1.355 de 30 de dezembro de 1994. Ata Final que Incorpora os Resultados da Rodada Uruguai de Negociações Comerciais Multilaterais do GATT. Diário Oficial da União, Brasília, DF, 31 dez. 1994. Seção I, p. 21.394.

BRASIL. Decreto n. 3551 de 04 de agosto de 2000. Institui o Registro de Bens Culturais de Natureza Imaterial que constituem patrimônio cultural brasileiro, cria o Programa Nacional do Patrimônio Imaterial e dá outras providências. Diário Oficial da União, Brasília, DF, 7 ago. 2000. Seção 1, p. 2.

BRASIL. Lei. 7.347 de 24 de julho de 1985. Disciplina a ação civil pública de responsabilidade por danos causados ao meio-ambiente, ao consumidor, a bens e 
direitos de valor artístico, estético, histórico, turístico e paisagístico e dá outras providências. Diário Oficial da União, Brasília, DF, 25 jul. 1985. Seção 1, p. 10.649.

BRASIL. Lei n. 10.406 de 10 de janeiro de 2002. Institui o Código Civil. Diário Oficial da União, Brasília, DF, 11 jan. 2002. Seção 1, p. 1.

BRASIL. Lei n. 9.279 de 14 de maio de 1996. Lei da Propriedade Industrial. Diário Oficial da União, Brasília, DF, 15 maio 1996. Seção 1, p. 8.353.

CARDOSO, Oscar Valente. A competência da Justiça Federal na tutela dos direitos da propriedade intelectual. Revista CEJ, Brasília, ano XII, n. 43, p. 51-56, out./dez. 2008.

CARLS, Suelen. Proteção jurídica das indicações geográficas e desenvolvimento: 0 regulamento de uso e as estruturas de controle e gestão. $217 \mathrm{f}$. Tese (Doutorado em Direito) - Universidade Federal de Santa Catarina, Florianópolis, 2016.

FABRIS, Jonas; MACHADO, Gláucio José Couri; GOMES, Iracema Machado de Aragão. Evolução da proteção dos produtos tradicionais. Revista GEINTEC - Gestão, Inovação e Tecnologias, v. 2, n. 4, p. 387-395, 2012.

FIGUEIREDO, Isabel et al. Capim Dourado. Design popular do Jalapão. Manejo comunitário sustentável. Catálogo, PEQUI - Pesquisa e Conservação do Cerrado. 2009. Disponível em: www.centraldocerrado.org.br/blog/wpcontent/uploads/2009/03/catalogo-capim-dourado.pdf. Acesso em: 3 mar. 2019.

GOMES, Magno Federici; DUTRA, Walter Veloso. Meio ambiente cultural, regulação, poder administrativo sancionador e responsabilidade civil do Estado. Revista Direito Ambiental e Sociedade, Caxias do Sul, v. 7, n. 2, p. 83-117, maio/ago. 2017.

GOMES, Rita de Cássia Medeiros. O direito e a propriedade intelectual: constitucionalização, campo de atuação e responsabilidade a violação do direito. PIDCC - Revista de Propriedade Intelectual - Direito Contemporâneo e Constituição, Aracaju, ano IX, v. 1, n. 01, p. 60-82, fev. 2020.

LIMA, Thaisi Leal Mesquita de; GUIMARÃES, Patrícia Borba Vilar; DANTAS, Thomas Kefas de Souza. Análise jurídica e socioeconômica acerca da importância da indicação geográfica no Brasil. PIDCC - Revista de Propriedade Intelectual - Direito Contemporâneo e Constituição, Aracaju, v. 9, n. 2, p. 434-461, jun. 2015.

MELLO, Janaina Cardoso. Artesanato em Capim Dourado na Região do JalapãoTocantins: trabalho \& indicação de procedência (IP) em tempos de globalização. Política \& Trabalho, n. 43, 2015.

N.P. CAPIM D’ORO, Itália, N. D. Disponível em: capimdoro.com. Acesso em: 20 fev. 2020. 
NIEDERLE, Paulo André. Desenvolvimento, instituições e mercados agroalimentares: os usos das indicações geográficas. DRd - Desenvolvimento Regional em Debate, Canoinhas, v. 4, n. 2, p. 21-43, jul./dez. 2014.

PERALTA, Patrícia P. Necessidade de políticas institucionais para a aplicação de Indicações Geográficas como instrumentos de proteção e valorização do Patrimônio Cultural. In: SEMINÁRIO INTERNACIONAL POLÍTICAS CULTURAIS, 7., 17 a 20 de maio de 2016, Rio de Janeiro. Anais [...]. Rio de Janeiro: Fundação Casa de Rui Barbosa, 2016.

PIZZIO, Alex; LOPES, José Rogério. Controversias sobre la certificación de indicación geográfica del oro vegetal de Jalapão: el caso de la comunidad Mumbuca, Mateiros (TO). Cultura y Representaciones Sociales, México, v. 13, n. 25, p. 140-169, sept. 2018.

SEBRAE; INPI. Indicações geográficas brasileiras: artesanato. Brasília: Sebrae, 2014.

SILVA, Luécia Pereira; RODRIGUES, Waldecy. A indicação geográfica dos artesanatos em capim dourado da região do Jalapão do estado do Tocantins sob o enfoque dos princípios da boa governança dos commom-pool-resource. G\&DRRevista Brasileira de Gestão e Desenvolvimento Regional, Taubaté, v. 13, n. 3, p. 325, set./dez. 2017.

STRASBURG JÚNIOR, Carlos Edson. Da importância das indicações geográficas no atual contexto da empresa agrária. 136 f. Dissertação (Mestrado em Direito Civil) Universidade de São Paulo, São Paulo, 2013.

TOCANTINS. Lei n. 1.172 de 31 de julho de 2000. Cria a Unidade de Conservação denominada de APA - Jalapão. Diário Oficial do Estado do Tocantins, n. 958.

TOCANTINS. Lei n. 1.203 de 12 de janeiro de 2001. Cria o Parque Estadual do Jalapão. Diário Oficial do Estando do Tocantins, n. 1.004.

TOCANTINS. Lei n. 3594 de 18 de dezembro de 2019. Dispõe sobre a Política Estadual de Uso Sustentável do Capim-Dourado e do Buriti, e adota outras providências.

Diário Oficial do Estado do Tocantins, Palmas, Tocantins, 20 dez. 2019.

TOCANTINS. Portaria n. 362, de 25 de maio de 2007. Estabelece normas para a coleta e manejo do capim dourado. Diário Oficial do Estado do Tocantins, Palmas, Tocantins, n. 2.418, p. 46, 31 maio 2007.

TOCANTINS. Regulamento geral de uso da indicação geográfica do artesanato do capim dourado no Jalapão. Não publicado. 2008.

TOCANTINS. Portaria n. 04 de 18 de fevereiro de 2009. Dispõe acerca da delimitação da área de indicação geográfica do capim dourado, da Região do Jalapão, estabelece o Registro da indicação, aprova o Regulamento Técnico para aferição dos padrões de identidade e qualidade do artesanato em capim dourado e dá outras 
providências. Diário Oficial do Estado do Tocantins, Palmas, Tocantins, ano XXI, n. 2.851, p. 16-21, 11 mar. 2009.

Alex Pizzio. Universidade Federal do Tocantins. Programa de Pós-Graduação em Desenvolvimento Regional. Email: alexpizzio@gmail.com

Aline Marinho Bailão Iglesias. Juíza no Tribunal de Justiça do Estado do Tocantins, Doutoranda no Programa de Pós-Graduação em Desenvolvimento Regional - da Universidade Federal do Tocantins -UFT. Email: aline.bailao.iglesias@gmail.com

Como citar: PIZZIO, Alex; IGLESIAS, Aline Marinho Bailão. A proteção jurídica de artesanias certificadas com registro de Indicação Geográfica e o caso da certificação do artesanato do capim dourado das comunidades tradicionais do Jalapão (TO). Redes (St. Cruz Sul, Online), Santa Cruz do Sul, v. 25, p. 1458-1476, nov. 2020. ISSN 1982-6745. doi:https://doi.org/10.17058/redes.v25i4.15178.

\section{CONTRIBUIÇÃO DE CADA AUTOR}

a. Fundamentação teórico-conceitual e problematização:

A fundamentação teórica do artigo foi amplamente discutida entre os dois autores. A autora Aline Iglesias contribui com a fundamentação referente a legislação brasileira e responsabilidade civil e penal e administrativa. O autor Alex Pizzio contribuiu mais com aplicação prática da lei, tais como: dificuldades que os sujeitos possuem para efetivar registros, compreensão do que realmente está envolvido etc. e aportou fundamentação aos estudos da comunidade e ao Capim Dourado, que têm sido objeto de suas investigações.

b. Pesquisa de dados e análise estatística:

Os dados levantados para a artigo foram feitos em conjunto. A autora Aline Iglesias se ocupou mais do levantamento de leis e normativas enquanto o autor Alex Pizzio se ocupou mais do levantamento de dados de campo.

c. Elaboração de figuras e tabelas:

Não se aplica.

d. Fotos:

Não se aplica.

e. Elaboração e redação do texto:

A elaboração do texto foi feita em conjunto a quatro mãos e é inseparável. Nenhum tópico foi elabora unicamente por um autor. Todos os c tópicos contam com revisões e contribuições de ambos os autores.

f. Seleção das referências bibliográficas:

Como já antecipado no item "a" cada autor contribui com as bibliografias que compõem a fundamentação teórica de cada tópico específico.

Fontes de financiamento: Tribunal de Justiça do Estado do Tocantins - TJTO 